\title{
O TRATADO SOBRE A LUZ de Roberto Grosseteste
}

\author{
CARLOS ARTHUR RIBEIRO DO NASCIMENTO
}

Roberto Grosseteste (1168 - 1253) (1) é tido em geral como uma das principais figuras da Universidade de Oxford no século XII. Sua importância é tanto mais significativa para o movimento cultural que se desenvolveu em torno desta universidade quanto se pode incontestavelmente atribuir a ele um certo número de características que balizaram tal movimento por vários séculos: recurso às fontes neo-platônicas, importância da matemática como chave do estudo da natureza, relevância da ótica como modelo de conhecimento matematizado do mundo material.

O texto que aqui apresentamos é de capital importância para a compreensão de Grosseteste e do movimento filosófico-científico por ele inspirado. Nele são lançadas as bases que sustentarão as especulações de Grosseteste, Rogério Bacon, João Pecham e muitos outros ${ }^{(2)}$.

O Tratado sobre a luz, nos parece, ao primeiro contato, um texto estranho. Não é nem um texto científico nem filosófico, no sentido que estas palavras assumem na atualidade. Grosseteste parece no entanto considerá-lo um texto de "filosofia". É o que indicariam certas expressões como as seguintes:

Esta foi, como suponho, a percepção dos filósofos que afirmaram que tudo é composto de átomos e que disseram que os corpos são compostos de super-

(1) Para umi informação de conjunto sobre Grosseteste pode-se consultar P. BOEHNER e E. GILSON, História da filosofia cristã. Petrópolis, Vozes, 1970, pp. 363.-376.

(2) Lembramos que o tratado do mundo de Descartes ainda terá por título: Le monde ou traité de la lumière. 
fícies, as superfícies de linhas e as linhas de pontos (p. 53, lin. 36-p.54, lin. 1; grifo nosso) ${ }^{(3)}$.

Todos porém que filosofam corretamente afirmam que a terra é imune deste movimento (circunrotação diurna) (p. 57, lins. 28-29; grifo nosso) .

Ora, as frases em que estas expressões aparecem evocam para nós muito mais o domínio que costumamos reservar à ciência. Devemos portanto nos guardar de impor ao texto as categorias posteriores de ciência e filosofia. A "filosofia" de Grosseteste é um domínio que abarca indistintamente os setores distinguidos por estas categorias posteriores.

O assunto global do Tratado sobre a luz pode ser caracterizado sem muita infidelidade como sendo uma hipótese cosmogônica, uma tentativa de tornar inteligível ao nível da "filosofia" a gênese do universo. $\mathrm{Na}$ exposição mesclam-se análises de caráter predominantemente ontológico (p. 51, lin. 10-p. 52, lin. 21), considerações de ordem matemática (p. 52, lin. 32-p. 53, lin.35) e formulações que se aparentariam mais a uma hipótese científica sobre a origem do cosmos (p. 54, lin. 11-p. 57, lin. 8) .

Conviria ainda notar o uso feito da matemática. Grosseteste faz apelo a razões matemáticas para explicar questões de ordem física. Mas a aplicação da matemática ao domínio físico se faz por uma espécie de aproximação comparativa ou por transposição ao domínio físico das relações verificadas na ordem propriamente matemática (cf. p. 52, lin. 32-p. 53, lin. 35 e p. 53, lin. 36-p. 54, lin. 10). Talvez esta maneira de transpor a matemática ao domínio físico não esteja longe da exegese alegórica que se faz notar a propósito da terra (p. 56, lins. 23-31) . E assume caráter nitidamente numerológico na parte final do texto (p. 58, lin. 8-p. 59, lin. 2).

(3) Como base para a tradução utilizamos o texto crítico do De luce publicado por L. BAUR, Die philosophischen Werke des Robert Grosseteste, in Beiträge zur Geschichte der Philosophie des Mittelalters, IX (1912), pp. 51-59. Servimo-nos também da tradução inglesa de C. RIEDL reproduzida em A. HYMAN e J. T. WALSH, Philosophy in the Middle Ages, N. York, Harper and Row, 1967, pp. 434-440.

As referências indicam a's páginas e linhas da edição Baur reproduzidas na margem de nossa tradução. 
Com a finalidade de facilitar a abordagem do texto do Tratado sobre a luz propomos a sua divisão de seguinte maneira :

1. A luz, primeira forma corporal p. 51, lin. 10-p. 54, lin. 10

1.1 A luz como forma p. 51, lin. 10-p. 52,lin. 21

1.1.1 Primeiro argumento p. 51, lin. 10-p.52, lin. 9

1.1.2 Segundo argumento p. 52, lins. 10-16

1.1.3 conclusão p. 52 , lins. $17-21$

1.2 Processo de extensão da matéria pela luz p. 52, lin. 21-p. 54, lin. 10

1.2.1 Realizada por uma multiplicação infinita p. 52, lins. 21-31

1.2.2 Proporções encontradas nesta multiplicação p. 52, lin. 32-p. 53, lin. 35

1.2.3 Apêndice histórico p. 53, lin. 36-p. 54, lin. 10

2. Gênese do universo p. 54, lin. 11-p. 57, lin. 8

2.1 Formação do universo p. 54, lin. 11-p. 56, lin. 13

2.1.1 Generalidades p. 54, lins. 11-17

2.1.2 Formação do primeiro corpo (supremo) ou firmamento p. 54, lins. 18-30

2.1.3 Formação da segunda esfera p. 54, lin. 31-p. 55, lin. 22

2.1.4 Formação das esferas subseqüentes até a nona p. 55, lins. 23-30

2.1.5 Formação dos quatro elementos abaixo da nona e ínfima esfera p. 55, lin. 30-p. 56, lin. 13

2.2 Resumo sobre as treze esferas p. 56, lin. 14-p. 57, lin. 8

2.2.1 Em geral; o primeiro corpo p. 56, lins. 14-22

2.2.2 A terra p. 56, lins. 23-31

2.2.3 Os corpos intermediários p. 56, lins. 31-35

2.2.4 A luz como espécie e perfeição de todos os corpos p. 56, lin. 36-p. 57, lin. 4 


\subsubsection{Apêndice histórico p. 57, lins. 5-8}

3. Movimento dos corpos do universo p. 57, lin. 9-p. 58, lin. 7

3.1 Movimento diurno das esferas p. 57 lins. 9-18

3.2 Movimento dos elementos p. 57, lins. 19-29

3.3 Participação das demais esferas no movimento da segunda p. 57, lins. 30-33

3.4 Distinção entre o movimento das esferas e dos quatro elementos p. 57, lin. 34-p. 58, lin. 7

4. Os quatro princípios de toda realidade p. 58, lin. 8-p. 59, lin. 2
4.1 No corpo supremo (primeira esfera ou firmamento) p. 58 , lins . 8-28

4.2 Nos demais corpos p. 58, lin. 29 - p. 59, lin. 2

\section{SOBRE A LUZ OU A GÊNESE DAS FORMAS}

5110 Julgo que a primeira forma corporal, que alguns chamam de corporeidade, é a luz. De fato, por si a luz se difunde a si mesma por toda parte de tal modo que, se nada de opaco se opuser, de um ponto de luz gera-se instantaneamente uma esfera de luz qual for a grandeza desta última. Ora, a corporeidade é aquilo a que se segue necessariamente a extensão 15 da matéria segundo as tres dimensões, embora ambas, isto é, a corporeidade e a matéria sejam substâncias em si mesmas simples, destituídas de toda dimensão. Mas era impossível que a forma, em si mesma simples e destituída de dimensão, introduzisse por toda parte a dimensão na matéria igualmente simples e destituída de dimensão, a não ser que ela se multipli20 casse a si mesma e se difundisse instantaneamente por toda parte e, na sua difusão, estendesse a matéria, já que a própria forma não pode deixar a matéria porque não é separável, nem a própria matéria pode ser despida de forma. - Ora, propus que é a luz que tem como operação própria multiplicar-se a si mesma e difundir-se instantaneamente por toda parte. Por- 
tanto, o que quer que seja que realize esta obra, ou é a própria luz, ou é capaz de realizar esta obra enquanto participa da luz que a faz por si mesma. Portanto, a corporeidade, ou é a própria luz, ou é o supra-citado realizador desta obra e introdutor 5 das dimensões na matéria, enquanto participa da própria luz e age por virtude dela. Ora, é impossível que a forma primeira introduza as dimensões na matéria por virtude de uma forma conseqüente a si mesma. Portanto, a luz não é uma forma conseqüente à corporeidade, mas é a própria corporeidade.

10 Além disso, julgam os entendidos que a primeira forma corporal é mais digna que todas as formas consequentes, de essência mais excelente e mais nobre e mais se assemelha às formas que existem separadas. Ora, a luz é de essência mais digna, mais nobre e mais excelentes que todas as realidades

15 corporais, se assemelha mais do que todos os corpos às formas que existem separadas que são as inteligências. Portanto, a luz é a primeira forma corporal.

Portanto, a luz, que é a primeira forma criada na matéria prima, multiplicando-se infinitamente a si mesma por si mesma de todos os lados e estendendo-se igualmente por toda

20 parte, no princípio do tempo estendia a matéria, da qual não podia se desligar, distendendo-a consigo à grandeza equivalente à máquina do mundo. A extensão da matéria não pode também ter sido realizada por uma multiplicação finita da luz, pois, algo simples, reproduzido finitamente, não dá origem a uma grandeza, como o mostra Aristóteles no Tratado sobre o céu (1,5-7). Mas, infinitamente multiplicado, neces-

25 sáriamente produz uma grandeza finita, pois o produto da multiplicação infinita de algo excede ao infinito aquilo por cuja multiplicação é produzido. Ora, algo simples não é excedido ao infinito por algo simples, mas apenas uma grandeza finita excede ao infinito o que é simples. Pois uma grandeza infinita excede infinitamente ao infinito o que é simples.

30 - Portanto, a luz, que em si é simples, infinitamente multiplicada, necessariamente estende a matéria, igualmente simples, nas dimensões de uma grandeza finita.

$\dot{E}$, no entanto, possível que um conjunto infinito de números mantenha com outro conjunto infinito todas as proporções racionais e mesmo todas as irracionais. Há infinitos

35 maiores do que outros e outros infinitos que são menores do que outros. O conjunto de todos os números tanto pares como 53 ímpares é infinito e, portanto, maior que o conjunto de todos os números pares (que no entanto é infinito), pois excede este 
último pelo conjunto de todos os números ímpares. Também 5 o conjunto contínuo dos números duplos a partir da unidade é infinito; e igualmente é infinito o conjunto de todos os meios correspondentes a estes duplos. E o conjunto destes meios é necessariamente metade do conjunto dos seus duplos. De modo semelhante o conjunto de todos os números triplos a partir da unidade é triplo em relação ao conjunto de todos os terços 10 correspondentes a estes triplos. - O mesmo se evidencia de todas as espécies de proporção racional, pois, segundo qualquer uma delas, o finito pode relacionar-se com o infinito.

Se se supuser porém o conjunto infinito contínuo de todos os duplos a partir da unidade e o conjunto infinito de

15 todos os meios correspondentes a estes duplos; tirando-se do conjunto dos meios a unidade ou qualquer número finito, uma vez feita a subtração, não haverá mais entre o primeiro conjunto e o resto do segundo uma proporção dupla. Nem nenhuma outra proporção racional porque, se se deixar outra proporção racional por subtração de uma parcela do extremo 20 menor de uma proporção racional, a parcela subtraída deve ser uma ou algumas partes aliquotas do número de que é subtraída. Ora, um número finito não pode ser uma ou algumas partes aliquotas de um número infinito. Portanto, subtraído um número do conjunto metade infinito, não permanece nenhuma proporção racional entre o conjunto duplo 25 infinito e o resto do conjunto metade infinito.

Posto isto, é manifesto que a luz, pela sua multiplicação infinita, estende a matéria nas dimensões finitas menores e nas dimensões finitas maiores, relacionando-se entre si se30 gundo quaisquer proporções racionais ou não. Com efeito, se a luz pela sua multiplicação infinita, estende a matéria numa dimensão de dois côvados, pela mesma multiplicação infinita duplicada, ela a estende numa dimensão de quatro côvados e, pela metade da mesma multiplicação infinita, a estende numa dimensão de um côvado; o mesmo se dando quanto às 35 demais proporções racionais e irracionais.

Esta foi, como suponho, a percepção dos filósofos que afirmaram que tudo é composto de átomos e que disseram que os

54 corpos são compostos de superfícies, as superfícies de linhas e as linhas de pontos. - Esta posição não contradiz a afirmação de que a grandeza só é composta de grandezas, pois há tantas espécies de todo quantas são as espécies de parte. De fato, a metade é denominada "parte do todo" num sentido, 5 pois, tomada duas vezes, restitui o todo; em outro sentido, o 
lado é "parte da diagonal", pois, tomado como partes não aliquotas restitui a diagonal, mas tomado um certo número de vezes é ultrapassado pela diagonal. E o ângulo de tangência é denominado "parte do ângulo reto", no qual está contido infinitas vezes, num sentido, pois, dele subtraído finitamente, o diminui; e noutro sentido o ponto é "parte da linha" na 10 qual está contido infinitas vezes e, dela subtraído finitamente, não a diminui.

Voltando portanto ao nosso assunto, digo que a luz, pela multiplicação infinita de si mesma, feita igualmente em todas as direções, estende a matéria igualmente por toda parte na forma de uma esfera. Segue-se necessariamente desta 15 extensão que as partes extremas da matéria são mais estendidas e mais rarefeitas do que as partes interiores e próximas do centro. Quando as partes extremas estiverem rarefeitas ao máximo, as partes interiores ainda serão suscetíveis de maior rarefação.

A luz, portanto, estendendo a matéria do modo como foi dito, numa forma esférica e rarefazendo as partes extremas 20 ao máximo, completou a possibilidade da matéria na esfera mais afastada não a deixando suscetível de uma impressão ulterior. Assim foi terminado o corpo primeiro, que é chamado firmamento, no contorno da esfera, nada tendo na sua composição senão a matéria prima e a forma primeira. Por isso é o corpo mais simples quanto às partes constituintes de

25 sua essência e quantidade máxima, não diferindo do gênero "corpo" senão pelo fato de que a matéria é completada somente pela forma primeira. Ora, o gênero "corpo", que está neste e nos demais corpos, tendo na sua essência a matéria prima e a forma primeira, abstrai da complementação da

30 matéria pela forma primeira e da coarctação da matéria pela forma primeira.

Asim completando o corpo primeiro que é firmamento, ele irradia sua luminosidade de todas suas partes para o centro do todo. Pois, sendo a luz a perfeição do primeiro corpo, naturalmente se multiplica a partir deste, necessariamente

35 difunde-se luz na direção do centro do todo. E, sendo ela uma forma não separável na sua totalidade da matéria na sua difusão a partir do corpo primeiro, estende consigo a espiritualidade do corpo primeiro. Assim procede do corpo primeiro a luminosidade que é um corpo espiritual ou, melhor dizendo, um espírito corporal. Esta luminosidade, no seu percurso, não divide o corpo pelo qual passa e por isso passa instanta- 
5 neamente do corpo do primeiro céu até o centro. O seu percurso não se dá como se se pensasse em algo de individual que passasse instantaneamente do céu ao centro - isto talvez seja de fato impossível - mas o seu percurso se dá pela multiplicação de si mesma e pela geração infinita de luminosidade. Portanto, a própria luminosidade irradiada do corpo primeiro para o centro do mundo, uma vez reunida,

10 congregou a massa existente abaixo do corpo primeiro. Como já não pudesse coarctar o corpo primeiro, por ser este completo e invariável, e como o lugar não pudesse ficar vazio, foi necesário que estendesse e separasse as mais afastadas desta massa ao congregá-la. Assim originava-se nas partes interiores da dita massa uma densidade maior, e nas mais afas-

15 tadas aumentava a rarefação. Foi tanta a potência da luminosidade que reunia esta massa e que, ao reunir, separava que as partes mais afastadas da massa contida abaixo do corpo primeiro se sutilizaram e rarefizeram ao máximo. Originava-se assim nas partes mais afastadas da dita massa, a segunda esfera, completa e não receptível de nenhuma im-

20 pressão ulterior. Tal é o complemento e a perfeição da segunda esfera: com efeito, luminosidade é gerada pela primeira esfera e a luz que na primeira esfera é simples, na segunda é duplicada.

Assim como a luminosidade gerada pelo primeiro corpo completou a segunda esfera e, dentro desta, deixou uma massa

25 mais densa, igualmente a luminosidade gerada pela segunda esfera constituiu a terceira esfera e, dentro dela, deixou, por reunião, uma massa ainda mais densa. Nesta ordem, procedeu a reunião separativa até que se completassem nove esferas celestes e que se reunisse dentro da nona e ínfima esfera uma

30 massa condensada que seria a matéria dos quatro elementos. A esfera ínfima, que é a esfera da lua, gerando também luminosidade a partir de si, por meio dela, reuniu a massa contida sob si e, ao reuní-la, sutilizou e separou suas partes mais afastadas. Mas a potência desta luminosidade não foi tanta 35 que, ao reunir, separasse as partes mais afastadas ao máximo. Por isso permaneceu em toda parte desta massa a imperfeição e a possibilidade de receber reunião e separação. A parte suprema desta massa, não separada ao extremo, mas tornada fogo pela sua separação, permaneceu ainda como matéria dos elementos. Este elemento, gerando luminosidade e reunindo a massa contida sob si, separou as partes mais afastadas desta, 5 porém com uma separação menor do que a do próprio fogo; assim produziu o fogo. - O fogo por sua vez, gerando lumi- 
nosidade de si mesmo e reunindo a massa contida sob si, separou as partes mais afastadas desta massa, porém com uma separação menor do que a sua própria; assim produziu o ar. - O ar também gerando a partir de si um corpo espiritual ou espírito corporal e reunindo o que estava contido dentro 10 de si e, fazê-lo, separando suas partes mais afastadas, produziu a água e a terra. Como na água permaneceu mais força unitiva do que força separativa, a própria água permaneceu também pesada junto com a terra.

Deste modo foram trazidas ao ser as 13 esferas deste 15 mundo sensível: nove celestes, inalteráveis, inaumentáveis, ingeneráveis e incorruptíveis, pois são completas; quatro existentes de maneira contrária, isto é, alteráveis, aumentáveis, generáveis e corruptíveis, pois são incompletas. - Isto é patente visto que todo corpo superior, segundo a luminosi20 dade dele proveniente,é a espécie e a perfeição do corpo seguinte. E assim como a unidade é potencialmente todo número seguinte, igualmente o primeiro corpo, pela multiplicação da sua luminosidade, é todo corpo seguinte.

A terra porém e todos os corpos superiores por agregação em si das luminosidades superiores. Por isso ela é chamada

25 pelos poetas de Pan, isto é, "tudo"; é também denominada Cibele como se fosse um "leito" [cubile] que provém de "cubo", isto é, "solidez", pois ela é o mais compacto de todos os corpos; ela é Cibele, mãe de todos os deuses, porque embora nela estejam coligidas todas as luminosidades superiores, estas não estão ativas nela pelas suas operações, mas é possível a 30 partir dela conduzir ao ato e à operação a luminosidade de qualquer uma das esferas que se quiser. Assim qualquer um dos deuses se procriará dela como de uma mãe. - Os corpos intermediários porém mantêm uma dupla relação. Estão para com os inferiores como o primeiro céu em relação a tudo mais; para com os superiores, como a terra em relação a tudo mais. Assim, segundo certos modos, em cada um deles estão 35 todos os restantes.

A espécie e perfeição de todos os corpos é a luz: mais espiritual e simples quando se trata dos corpos superiores; mais corporal e multiplicado quando se trata dos inferiores.

57 Embora tenham procedido da luz simples ou multiplicada, nem por isso todos os corpos são da mesma espécie, assim como todos os números não são da mesma espécie, embora resultem da unidade por maior ou menor multiplicação. 
5 Com esta explicação talvez fique clara a intenção dos que dizem que "tudo é uno por causa da perfeição da luz única" e a intenção dos que dizem que "o que é múltiplo por causa da multiplicação diversa da luz".

Visto os corpos inferiores participarem da forma dos cor10 pos superiores, o corpo inferior, pela participação da mesma forma com o corpo superior, é capaz de ser movido pela mesma força motora incorporal pela qual é movido o corpo superior. Por isso, a força da inteligência incorpórea ou da alma, que move a primeira e suprema esfera com o movimento diurno, move todas as esferas celestes inferiores com o mesmo movi-

15 mento diurno. Mas quanto mais inferiores forem tanto mais debilmente recebem este movimento, pois quanto mais inferior for a esfera tanto menos pura e mais débil é nela a primeira luz corporal.

Embora os elementos participem da forma do primeiro céu, 20 não são movidos pelo motor do primeiro céu com o movimento diurno. Embora participem desta luz primeira, não obedecem à força motora primeira por terem esta luz impura, débil e distante da sua pureza no primeiro corpo e por terem também a densidade da matéria que é princípio de resistência e de desobediência. Pensam no entanto alguns que a esfera 25 do fogo está sujeita à circunrotação do movimento diurno e como sinal disto colocam a circunrotação dos cometas; dizem também que este movimento se estende até às águas do mar, de tal modo que dele proviria o fluxo dos mares. Todos porém que filosofam corretamente afirmam que a terra é imune 30 deste movimento.

Do mesmo modo as esferas que estão depois da segunda (que ordinariamente, segundo a enumeração feita de baixo para cima, é denominada oitava), visto participarem de sua forma, comungam no seu movimento, que lhes é atribuído, além do movimento diurno.

As esferas celestes por serem completas, não suscetíveis 35 de rarefação ou condensação, a luz nelas não faz as partes da matéria pender para fora do centro para rarefazê-las, nem as faz pender para o centro para condensá-las. Por isso as esferas celestes não são suscetíveis de movimento para cima ou para baixo, mas apenas de movimento circular proveniente da força motora intelectiva que refletindo corporalmente em si mesma a aparência, gira as esferas com uma revolução corporal. Visto porém os elementos serem incompletos, rare- 
5 factíveis e condensáveis, a luminosidade que neles está os faz pender, ou para fora do centro a fim de rarefazê-los, ou para o centro a fím de condensá-los. Por isso eles são naturalmente capazes de movimento seja para cima, seja para baixo.

No corpo supremo, que é o mais simples dos corpos, encontram-se quatro princípios: a forma, a matéria, a compo10 sição e o composto. A forma enquanto simplissíssima ocupa o lugar da unidade. - A matéria por causa de sua dupla capacidade, isto é, a suscetibilidade das impressões e a receptibilidade das mesmas, e também por causa da densidade, que radicalmente pertence à matéria, a qual em primeiro lugar e principalmente advém ao binário, reveste com razão a na15 tureza do binário. - A composição detém em si o ternáric, pois nela aparece a matéria formada, a forma materializada e a particularidade própria da composição que se encontra em todo composto como algo de terceiro distinto da matéria e da forma. - O que é o próprio composto, além destes tres, está

20 compreendido sob o número quaternário. - O quaternário está portanto no primeiro corpo no qual estão virtualmente os demais corpos e por isso, radicalmente, o número dos demais corpos não se encontra além do denário. De fato quando se somam a unidade da forma, o binário da matéria, o ternário da composição e o quartenário do composto, constituem 25 o denário. Por isso o denário é o número dos corpos das esferas do mundo porque, embora a esfera dos elementos divida-se em quatro, é una pela participação da natureza terrestre corruptível.

Fica assim patente que o denário é o número perfeito da 30 totalidade porque qualquer todo perfeito tem algo em si como forma e unidade, como matéria e binário, como composição e ternário, como composto e quaternário. Não sendo possível que, além destes quatro, se acrescente um quinto. Daí qualquer todo perfeito ser dez.

35 Por isso fica manifesto que somente as cinco proporções encontradas nestes quatro números (um, dois, três e quatro) são apropriadas à composição e à concordia estabelecedora de todo composto. Por isso só estas cinco proporções concordantes estão presentes nas medidas musicais, nas danças e no tempos rítmicos.

Termina o tratado sobre a luz do Lincolniense. 